\title{
A Tale of Two Tauopathies
}

Figure Brain MRI
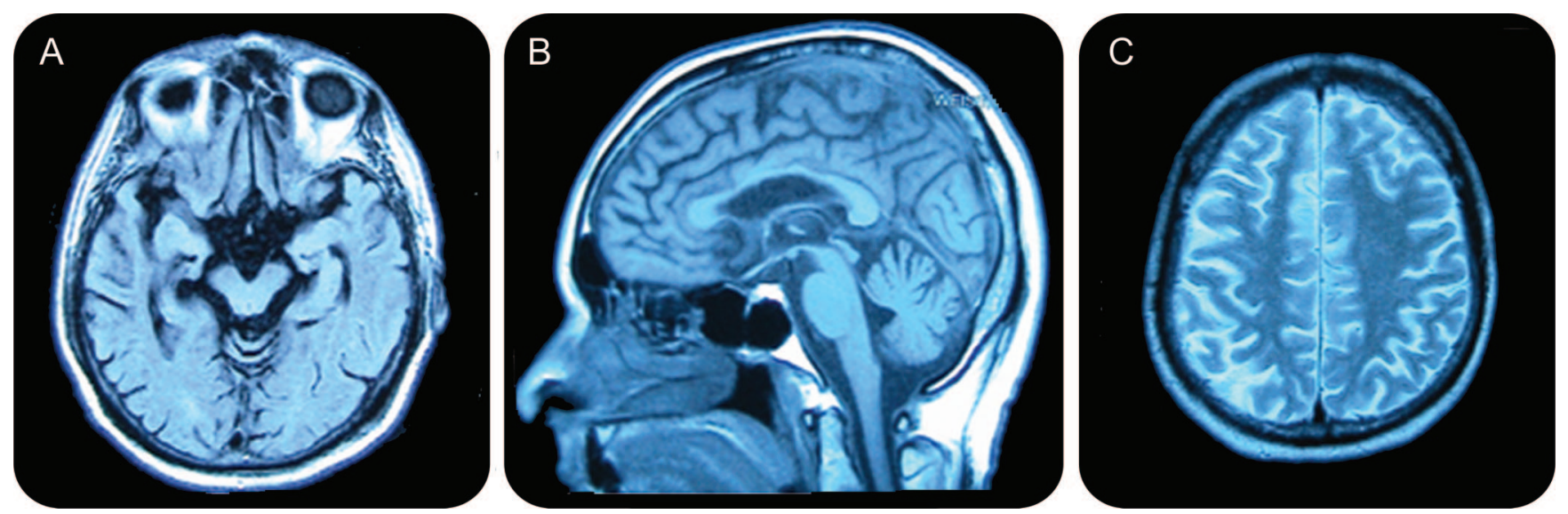

(A) Axial T1-weighted brain MRI shows atrophy of the lateral midbrain tegmentum. Described as the morning glory sign, showing similarity to the morning glory flower, it has been described in progressive supranuclear palsy (PSP). ${ }^{6}$ (B) Adjacent sagittal T1 images show atrophy in the midbrain and the characteristic hummingbird sign, also described as characteristic of PSP.7 (C) Axial T2-weighted brain MRI with asymmetric right frontoparietal atrophy. Asymmetric atrophy is a common finding in corticobasal degeneration/corticobasal syndrome and reflects cortical cell loss responsible for the cortical motor deficits of apraxia, myoclonus, and alien limb. ${ }^{4}$

\begin{abstract}
A 77-year-old man developed progressive language and balance difficulties. He had difficulty rising from a chair, with falls occurring within the first year of symptoms. After 1 year, rapid, spontaneous jerks appeared in the left hand, which he described as "useless." Neurologic examination 3 years after his initial symptoms demonstrated 23/30 on the Mini-Mental State Examination and an applause sign. He had apathy, without a pseudobulbar affect. Aside from mild word-finding difficulties, his language examination was normal. Cranial nerve examination showed vertical gaze limitation with loss of vertical fast phases on testing of optokinetic nystagmus $(\mathrm{OKN})$. Vertical gaze limitations could be overcome with oculocephalic maneuvers. Motor examination revealed markedly increased tone in his left arm, with moderate left greater than right bradykinesia, without tremor. Left ideomotor apraxia was present. Action and postural myoclonus was present in the left arm. There was neck extension and axial rigidity. Gait was slow and slightly wide-based with impaired postural reflexes. Stereognosis and graphesthesia were intact. A trial of levodopa/carbidopa $900 \mathrm{mg}$ per day showed no symptomatic benefit. Brain MRI without gadolinium revealed asymmetric, focal atrophy of the right frontoparietal area and the midbrain tegmentum (figure).
\end{abstract}

DISCUSSION OF DIAGNOSIS The patient presented with a progressive neurodegenerative disorder affecting multiple domains within cortical and subcortical systems. Postural instability, vertical supranuclear ophthalmoplegia, and an applause sign are characteristic of progressive supranuclear palsy (PSP). This disorder is a tauopathy often considered in the differential diagnosis of atypical parkinsonism. It should be suspected in elderly individuals who develop early falls (especially backwards), symmetric parkinsonism, and vertical supranuclear ophthalmoplegia. ${ }^{1}$

Loss of vertical fast phases with OKNs is an early sign of vertical gaze limitation in PSP. Also, the presence of an applause sign, indicating poor executive function, is common in PSP. ${ }^{2}$ The diagnosis of PSP is reasonable in this case; however, the development of marked, asymmetric rigidity with apraxia and focal myoclonus is atypical for PSP. Usually patients with PSP develop symmetric motor deficits and myoclonus is unusual. The "useless" left arm with apraxia and myoclonic jerks is more suggestive of corticobasal degeneration (CBD), another tauopathy closely related to PSP. Like PSP, CBD is considered in the differential diagnosis of atypical parkinsonism. ${ }^{3}$ Parkinson 


\section{Two Tauopathies}

- Progressive supranuclear palsy and corticobasal degeneration are tauopathies.

- PSP and CBD may overlap clinically in the same patient.

- Corticobasal syndrome does not consistently predict CBD neuropathology.
21 patients presenting with CBS, 10 had pathology consistent with $\mathrm{CBD}$, while another 10 had pathology consistent with PSP. From this study as well as others, it is clear that PSP and CBD have significant overlap in clinical presentation, making a clinical diagnosis challenging. ${ }^{4}$ Further studies are necessary to further delineate the phenotypes of these clinical syndromes.

Final diagnosis. Primary tauopathy with features of PSP and CBS.

disease (PD) should be considered; however, there are many red flags in this patient against a PD diagnosis, including early falls, vertical gaze impairment, levodopa nonresponsiveness, focal myoclonus, marked asymmetry of motor signs, and apraxia in the affected limb. Other considerations in patients presenting with a CBD or PSP phenotype include atypical presentations of multiple system atrophy (MSA) and frontotemporal dementia (FTD) to include FTD parkinsonism linked to chromosome 17. In our patient, the absence of autonomic dysfunction makes MSA unlikely, and the absence of marked language or behavioral problems argue against a FTD phenotype. Overall, the patient had atypical parkinsonism with characteristic signs of 2 closely related disorders: CBD and PSP.

Background of diagnosis. Both PSP and CBD are neurodegenerative disorders characterized by accumulation of tau-immunoreactive pathology. The diagnosis of $\mathrm{CBD}$ in movement disorders clinics is considered in patients who demonstrate asymmetric severe rigidity associated with cortical findings in the affected limb such as myoclonus, apraxia, and an alien limb syndrome. ${ }^{3}$ In contrast, the clinical diagnosis of PSP is based on the findings of progressive symmetric parkinsonism with early falls, vertical supranuclear ophthalmoplegia, axial rigidity, and dysarthria in an individual over the age of 40. ${ }^{1}$ The clinical phenotype of these disorders, especially CBD, has been questioned recently.

There are multiple reports of patients who develop progressive asymmetric limb rigidity with other motor findings suggestive of $\mathrm{CBD}$, but at autopsy had alternative diagnoses including Alzheimer disease (AD), Pick disease, and PSP. There is increased recognition that the corticobasal syndrome (CBS), i.e., the clinical presentation of asymmetric limb rigidity with apraxia, myoclonus, or alien limb, does not consistently predict the presence of CBD neuropathology. ${ }^{4}$ The recognition that $\mathrm{CBS}$ does not reliably predict $\mathrm{CBD}$ pathology is an important new development in the understanding of these disorders. Moreover, patients with CBD neuropathology at autopsy can frequently have clinical presentations resembling $\mathrm{AD}, \mathrm{PSP}$, and frontotemporal dementia. In an autopsy series from Josephs et al., ${ }^{5}$ of

\section{Jason S. Hawley, MD, Bradley J. Robottom, MD, William J. Weiner, $M D$}

From the Walter Reed Army Medical Center (J.S.H.), Washington, DC; and University of Maryland School of Medicine (B.J.R., W.J.W.), Baltimore.

Disclosure: Dr. Hawley is an active duty officer currently serving in the United States Army. Dr. Robottom receives research support from Chelsea Therapeutics and Solvay Pharmaceuticals, Inc./Abbott Pharmaceuticals. Dr. Weiner has served on scientific advisory boards for Santhera Pharmaceuticals and Rexahn Pharmaceuticals, Inc.; serves on the editorial boards of Parkinsonism and Related Disorders and Neurological Reviews, and as Editor of Treatment Options in Neurology; receives royalties from the publication of Neurology for the Non-Neurologist (6th edition, Kluwers/Lippincott, 2010), Parkinson's Disease: A Complete Guide for Patients and Family (2nd edition, Hopkins University Press, 2007), and Handbook of Clinical Neurology Hyperkinetic Disorders thera Pharmaceuticals, and 'Boehringer Ingelheim; and has provided expert testimony and served as a subject matter expert in legal proceedings.

Received September 22, 2010. Accepted in final form December 27, 2010.

Address correspondence and reprint requests to Dr. Robottom, University of Maryland School of Medicine, 110 S. Paca Street 3-S128, Baltimore, MD 21201; brobottom@som.umaryland.edu

\section{REFERENCES}

1. Litvan I, Agid Y, Calne D, et al. Clinical research criteria for the diagnosis of progressive supranuclear palsy (SteeleRichardson-Olszewski syndrome): report of the NINDSSPSP international workshop. Neurology 1996;47:1-9.

2. Dubois B, Slachevsky A, Pillon B, Beato R, Villalponda JM, Litvan I. "Applause sign" helps to discriminate PSP from FTD and PD. Neurology 2005;64:2132-2133.

3. Litvan I, Agid Y, Goetz C, Jankovic J, et al. Accuracy of the clinical diagnosis of corticobasal degeneration: a clinicopathologic study. Neurology 1997;48:119-125.

4. Ling H, O'Sullivan S, Holton JL et al. Does Corticobasal degeneration exist? A clinicopathological re-evaluation. Brain 2010;133:2045-2057.

5. Josephs KA, Petersen RC, Knopman DS, et al. Clinicopathologic analysis of frontotemporal and corticobasal degenerations and PSP. Neurology 2006;66:41-48.

6. Adachi M, Kawanami T, Ohshima H, et al. Morning glory sign: a particular MR finding in progressive supranuclear palsy. Magn Reson Med Sci 2004;15:125-132.

7. Groschel K, Kastrup A, Litvan I, Schulz JB. Penguins and Hummingbirds: midbrain atrophy in progressive supranuclear palsy. Neurology 2006;66:949-950. (Elsevier, 2011); has received research support from Novartis, San- 


\title{
Neurology
}

\author{
A Tale of Two Tauopathies \\ Jason S. Hawley, Bradley J. Robottom and William J. Weiner \\ Neurology 2011;76;S67-S68 \\ DOI 10.1212/WNL.0b013e31820d57d9
}

This information is current as of February 14, 2011

\section{Updated Information \& Services \\ Supplementary Material \\ References \\ Subspecialty Collections}

\section{Permissions \& Licensing}

Reprints including high resolution figures, can be found at: http://n.neurology.org/content/76/7_Supplement_2/S67.full

Supplementary material can be found at: http://n.neurology.org/content/supp1/2011/06/27/76.7_Supplement_2.S 67.DC1

This article cites 7 articles, 5 of which you can access for free at: http://n.neurology.org/content/76/7_Supplement_2/S67.full\#ref-list-1

This article, along with others on similar topics, appears in the following collection(s):

All Movement Disorders

http://n.neurology.org/cgi/collection/all_movement_disorders Corticobasal degeneration

http://n.neurology.org/cgi/collection/corticobasal_degeneration

Parkinson's disease/Parkinsonism

http://n.neurology.org/cgi/collection/parkinsons_disease_parkinsonism Progressive supranuclear palsy

http://n.neurology.org/cgi/collection/progressive_supranuclear_palsy

Information about reproducing this article in parts (figures,tables) or in its entirety can be found online at:

http://www.neurology.org/about/about_the_journal\#permissions

Information about ordering reprints can be found online:

http://n.neurology.org/subscribers/advertise

Neurology ${ }^{\circledR}$ is the official journal of the American Academy of Neurology. Published continuously since 1951, it is now a weekly with 48 issues per year. Copyright Copyright $@ 2011$ by AAN Enterprises, Inc.. All rights reserved. Print ISSN: 0028-3878. Online ISSN: 1526-632X.

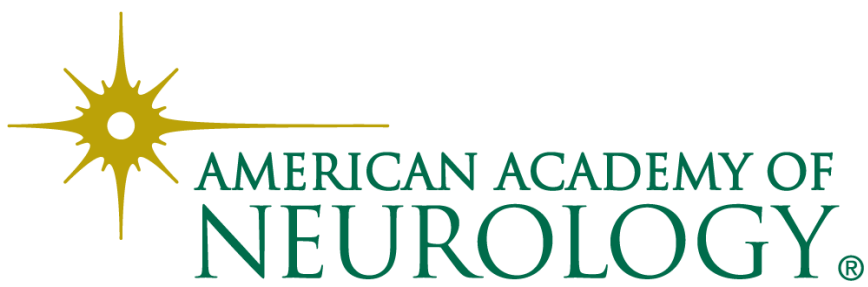

